\title{
Yapay Sinir Ağları ve Çoklu Doğrusal Regresyon Kullanarak Emeklilik Fonu Net Varlık Değerlerinin Tahmin Edilmesi Araştırma Makalesi/Research Article
}

\author{
Mehmet KAYAKUŞ ${ }^{*}$, (D) Mustafa TERZİOĞLU ${ }^{2}$ \\ ${ }^{1} Y$ önetim Bilişim Sistemleri Bölümü, Sosyal ve Beşerî Bilimler Fakültesi, Akdeniz Üniversitesi, Antalya, Türkiye) \\ ${ }^{2}$ Muhasebe ve Vergi Bölümü, Korkuteli MYO, Akdeniz Üniversitesi, Antalya, Türkiye) \\ mehmetkayakus@akdeniz.edu.tr, mterzioglu@akdeniz.edu.tr \\ (Geliş/Received:27.05.2020; Kabul/Accepted:19.01.2021) \\ DOI: $10.17671 /$ gazibtd.742995
}

\begin{abstract}
Özet-Bu çalışmada Türkiye'de faaliyet gösteren ve atak portföy yapısı ile tanımlanan 12 bireysel emeklilik fonunun Aralık 2005- Ocak 2020 dönemi arasında aylık olarak net varlık değerleri (NAV) çok katmanlı algılayıcı (ÇKA) ve çoklu doğrusal regresyon yöntemleriyle tahmin edilmeye çalışılmıştır. Bunun için 12 bağımsız değişken ve bir bağımlı değişkenden oluşan modeller oluşturulmuş; elde edilen sonuçların başarı oranları ve hata değerleri karşılaştırılmıştır. ÇKA yönteminde giriş katmanında 12 düğüm, 2 gizli katman ve her gizli katmanda 5 düğüm ve çıkış katmanında bir düğüm olan bir ağ modeli tasarlanmıştır. Tasarlanan bu ağ modelinde gizli katma sayısı ve her gizli katmandaki nöron sayısı aynıdır. Çoklu doğrusal regresyon modelinde 12 bağımsız değişken ile bir bağımlı değişken arasındaki bağıntıyı ortaya koymak ve tahminde bulunmak için her bir bireysel emeklilik yatırım fonunun net varlık değeri için bir model oluşturulmuştur. ÇKA ağının başarı oranı \%77,40, R2 0,986, RMSE 0,011, MAE 0,006, MAPE 0,076; ÇDR ise başarı oranı ise \%44,54, R2 0,981, RMSE 0,024, MAE 0,018, MAPE 0,400 olmuştur. Bu çalışma sonucunda ÇKA'nın başarısının geleneksel ekonometrik bir yöntem olan doğrusal regresyona göre daha iyi olduğu sonucuna ulaşılmıştır. Elde edilen bu sonuçlar Türkiye'de bundan önceki yapilan çalı̧̧alar ile paralellik göstermektedir. Ayrıca bu çalı̧ma profesyonel fon yöneticiler için de yönettikleri fonların performansını sürdürülebilir hale getirmesi ve değişen ekonomik koşullara göre portföylerini oluşturmasında yardımcı olacağı düşünülmektedir.
\end{abstract}

Anahtar Kelimeler-Bireysel emeklilik fonu, çok katmanlı algılayıcı, çoklu doğrusal regresyon

\section{The Prediction of Pension Fund Net Asset Values Using Artificial Neural Networks and Multiple Linear Regression Methods}

\begin{abstract}
In the present study, the researched attempted to estimate the net asset value (NAV) of 12 private pension funds operating in Turkey and described in the attack portfolio structure, covering the December 2005-January 2020 period using the multilayer perceptron (MLP) and multiple linear regression methods. To this end, models, comprised of 12 independent variables and one dependent variable were formed, and the success rates and error values of results were compared. A network model was designed in the MLP method, and this model consisted of 12 nodes in the input layer, 2 hidden layers with 5 nodes each, and one node in the output layer. An econometric model was created to identify and estimate the relationship between 12 independent variables and one dependent variable in the multiple linear regression model. The success rate of the MLP network is 77.40\%, R2 0.986, RMSE 0.011, MAE 0.006, MAPE 0.076; on the other hand, the success rate of MLR was 44.54\%, R2 0.981, RMSE 0.024, MAE 0.018, and MAPE 0.400. It was concluded in the study that the success rate of MLP was higher than linear regression, a traditional econometric method. These results are in parallel with those of previous studies in Turkey. In addition, the present study will be able to help professional fund managers to maintain the performance of funds they manage and to create their portfolios according to changing economic conditions.
\end{abstract}

Keywords-Pension fund, artificial neural networks, multiple linear regression 


\section{GİRIŞ (INTRODUCTION)}

Türkiye'de 2020 yılı itibariyle bireysel emeklilik sistemi (BES) yaklaşık 7 milyon kişiye ve bu sistemin toplam değeri 130 Milyar TL'ye ulaşmıștır [1]. Bu verilerden de görüleceği gibi sistem, toplum içerisinde kabul görmektedir. Bireyler, emeklilik döneminde refah seviyelerinde herhangi bir düşüş yaşamamak için sisteme başvurmaktadır. Bireysel emeklilik sisteminde fon şirketleri, bilindiği gibi emeklilik fonlarını farklı yatırımcı kişiliklerine oluşturmaktadır. Muhafazakâr yatırımcılar sabit getirili emeklilik fonlarını tercih etmekte, agresif yatırımcılar ise risk iştahı ile birlikte değişken portföylü ve riski yüksek emeklilik fonlarına yatırım yapmaktadır. $\mathrm{Bu}$ yüzden riski yüksek emeklilik fonlarının başarısı ve tahmini getirisi sabit getirili fonlara göre daha önemlidir. Bu tür emeklilik fonlarına literatürde atak/agresif emeklilik fonları denilmektedir. Atak emeklilik fonlarının başarısının temel kriteri piyasa riski, likidite riski, korelasyon riski, yoğunlaşma riski, opsiyon duyarlılık riski gibi riskleri öngörebilmesine bağlı bulunmaktadır. Bu atak emeklilik fonların gelecekteki değerlerinin tahminlenmesinde yukarıda belirtilen risklerin ortaya çıkmasına neden olan makroekonomik değişkenler, menkul kıymetler borsası endeks değerleri ve alternatif yatırım enstrümanlarının getirileri büyük önem taşımaktadır.

Çalışmada Sermaye Piyasası Kurulu'nun aylık bültenlerinden derlenen 12 adet atak emeklilik yatırım fonu incelenmektedir. Araştırmada bu emeklilik fonların seçilmesinin temel nedeni, Aralık 2005'ten beri herhangi bir birleșmeye maruz kalmaması, sadece satın almalarının ve yasal isim değişikliklerinin bulunmamasıdır. Bu durum emeklilik fonlarının net varlık değerlerinde (NAV) birleşmeden dolayı bir değişim yaratmayacağı için çalışmanın daha başarılı ve sağlıklı olmasını sağlamaktadır. Araştırmanın aralığı bu fonların hepsinin de aynı anda işlem gördüğü Aralık 2005 ve Ocak 2020'dir. Tablo 1'de bu emeklilik fonlarının çalışmanın başlangıç tarihindeki ve bitiş tarihindeki isimleri verilmektedir.

Bireysel emeklilik sisteminde 2005 y1lında atak emeklilik fonları büyüme amaçlı emeklilik fonları olarak tanımlanmaktadır. Günümüzde ise bu tip emeklilik yatırım fonları atak, dinamik değişken, dengeli değişken, hisse senedi ve karma emeklilik yatırım fonları olarak adlandırılmaktadır.

Şekil 1'de gösterilen ve araştırmaya konu olan emeklilik fonlarının reel getirileri Grafik 1'de gösterilmektedir.

Veri: Sermaye Piyasası Kurulu Raporları, Türkiye Cumhuriyet Merkez Bankası EVDS

Grafik 1'de görüldüğü gibi atak emeklilik fonları araştırmanın yapıldığı dönem içerisinde enflasyon üzerinde bir getiri sağlamıştır. Kümülatif olarak bu emeklilik fonları ilgili dönem içinde yaklaşık 2,5 ile 6,5 kat arasında büyüme sağlamışlardır. $\mathrm{Bu}$ durum bu emeklilik

\footnotetext{
${ }^{1}$ BA: Büyüme Amaçlı

2 EYF: Emeklilik Yatırım Fonu
}

fonlarına yöneten fon yöneticileri için bir başarı olarak kabul edilebilir.

Tablo 1. Araştırma yapılan fonların 2005 ve 2020 y1llarındaki isim değişiklikleri

(Title changes of the research pension funds in 2005 and 2020)

Aralık 2005 Emeklilik $\quad$ Ocak 2020 Emeklilik Fon Fon Ad 1 Ad1

\begin{tabular}{|c|c|}
\hline $\begin{array}{l}\text { Ak Emeklilik BA1 Esnek } \\
\text { EYF2 }\end{array}$ & $\begin{array}{l}\text { AVIVASA Dinamik } \\
\text { Değișken EYF }\end{array}$ \\
\hline $\begin{array}{l}\text { Ak Emeklilik BA Hisse } \\
\text { Senedi Grup EYF }\end{array}$ & $\begin{array}{l}\text { AVIVASA Hisse Senedi } \\
\text { Grup EYF }\end{array}$ \\
\hline $\begin{array}{l}\text { AHE3 BA Hisse Senedi } \\
\text { EYF }\end{array}$ & AHE Hisse Senedi EYF \\
\hline AHE BA Esnek EYF & AHE Atak Değişken EYF \\
\hline $\begin{array}{l}\text { AHE BA İkinci Esnek } \\
\text { EYF }\end{array}$ & $\begin{array}{l}\text { AHE Birinci Değişken } \\
\text { EYF }\end{array}$ \\
\hline $\begin{array}{c}\text { Başak Emeklilik BA } \\
\text { Hisse EYF }\end{array}$ & $\begin{array}{l}\text { FİBA Emeklilik Hisse } \\
\text { Senedi EYF }\end{array}$ \\
\hline $\begin{array}{c}\text { Garanti Emeklilik BA } \\
\text { Hisse Senedi EYF }\end{array}$ & $\begin{array}{c}\text { Garanti Emeklilik Hisse } \\
\text { Senedi EYF }\end{array}$ \\
\hline $\begin{array}{l}\text { Koç Allianz BA Esnek } \\
\text { EYF }\end{array}$ & $\begin{array}{l}\text { Allianz Hayat Dengeli } \\
\text { Değişken EYF }\end{array}$ \\
\hline $\begin{array}{c}\text { Oyak Emeklilik BA } \\
\text { Karma EYF }\end{array}$ & $\begin{array}{l}\text { NN Hayat Emeklilik } \\
\text { Karma EYF }\end{array}$ \\
\hline $\begin{array}{l}\text { Oyak Emeklilik BA Hisse } \\
\text { Senedi EYF }\end{array}$ & $\begin{array}{l}\text { NN Hayat Emeklilik } \\
\text { Hisse Senedi EYF }\end{array}$ \\
\hline $\begin{array}{l}\text { Vakıf Emeklilik BA } \\
\text { Hisse Senedi EYF }\end{array}$ & $\begin{array}{l}\text { Vakıf Emeklilik Hisse } \\
\text { Senedi EYF }\end{array}$ \\
\hline $\begin{array}{l}\text { Yap1 Kredi BA Hisse } \\
\text { Senedi EYF }\end{array}$ & $\begin{array}{l}\text { Allianz Yaşam Hisse } \\
\text { Senedi EYF }\end{array}$ \\
\hline
\end{tabular}

Grafik 1'de görüldüğü gibi atak emeklilik fonları araştırmanın yapıldığı dönem içerisinde enflasyon üzerinde bir getiri sağlamıştır. Kümülatif olarak bu emeklilik fonları ilgili dönem içinde yaklaşık 2,5 ile 6,5 kat arasında büyüme sağlamıșlardır. Bu durum bu emeklilik fonlarına yöneten fon yöneticileri için bir başarı olarak kabul edilebilir.

\section{LITERATÜR (LITERATURE)}

Literatürde hem emeklilik yatırım fonları hem de yatırım fonlarının tahmini ve bu tahmin metotlarının başarısı üzerine yapılan çalışmalar oldukça sınırlıdır. Çalışmanın bir amacı da literatüre katkı vererek bu alandaki bilimsel çalışmaların artmasını sağlamaktır. Özellikle geleneksel ekonometrik yöntemlerden ayrışan modern tahmin teknikleri, literatür araştırmamızda da görüldüğü gibi daha başarılı sonuçlar vermektedir.

Chiang ve diğerleri 1996'da yayımlanan çalışmalarında Amerika Birleşik Devletleri'ndeki 101 yatırım fonunun yılsonu NAV değerleri üzerinden 1981 ve 1986 yılını kapsayan yapay sinir ağları ve doğrusal regresyonu kullanarak bir modelleme yapmışlardır. Araştırmada bağımsız değişken olarak Gayrisafi Yurtiçi Hasıla, tüketici fiyat endeksi, sanayi üretim endeksi, işsizlik oranı gibi belli

${ }^{3}$ AHE: Anadolu Hayat Emeklilik 
başlı makro ekonomik değişkenler bağımlı değişken olarak da araştırmaya konu olan yatırım fonlarının NAV değerlerini kullanmışlardır. Çalışmanın sonucunda geleneksel ekonometrik bir modelleme yöntemi olan regresyon yöntemine göre yapay sinir ağlarının daha başarılı olduğu sonucuna ulaşmışlardır [2].

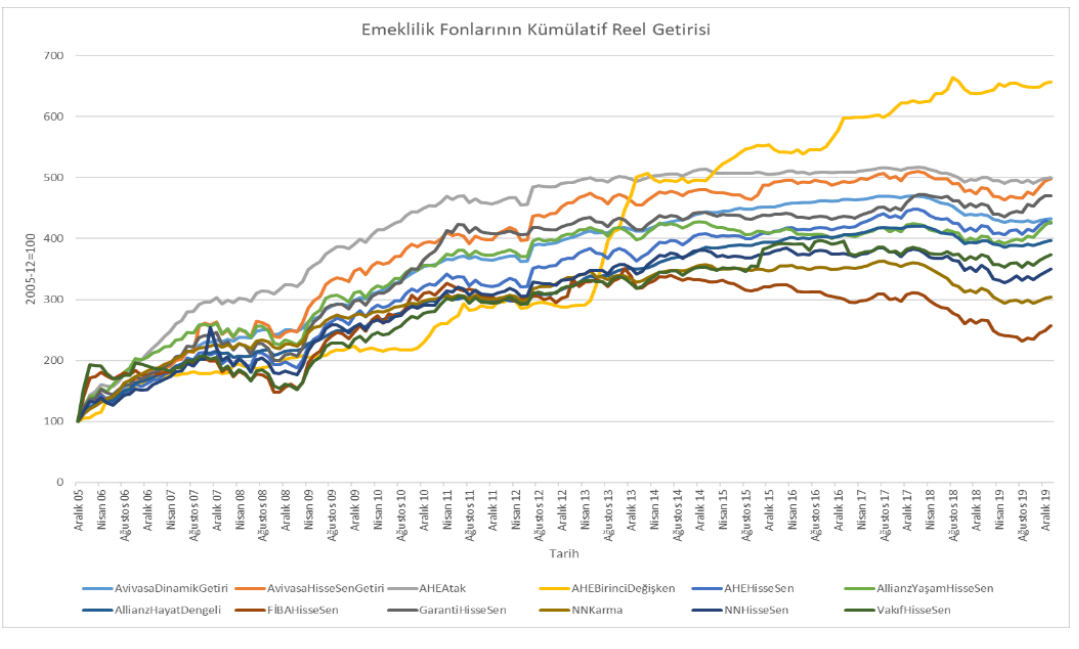

Şekil 1. Emeklilik fonlarının kümülatif getirisi, Aralık 2005=100

(Cumulative return of pension funds, December $2005=100$ )

Indro ve diğerleri 1999'da yayımlanmış olan araştırmalarında Morningstar yatırım fonları veri tabanında elde ettikleri 1993-1996 tarih aralığındaki hisse senedi ağırlıklı yatırım fonlarının değerini, büyümesini ve portföy oluşturma becerisini yapay sinir ağları ve doğrusal olmayan regresyon teknikleriyle test etmişlerdir. Elde ettikleri sonuçlarda yapay sinir ağlarının daha başarılı olduğu sonucuna ulaşmışlardır[3].

Ray ve Vani 2004 yllındaki sundukları bildiride Hindistan'da faaliyet gösteren 1999- 2004 dönemini kapsayan 10 adet yatırım fonunun NAV değerlerini bağımlı değişken olarak kullanmışlar; bağımsız değişken olarak da GSYİH, faiz oranı, enflasyon, döviz kuru, para arzı, hisse senedi piyasası işlem hacmi gibi çeşitli ekonomik değişkenlerin aylık verilerini kullanarak yapay sinir ağı modeli geliştirmişlerdir. Çalışmada, faiz oranı, para arzı, enflasyon oranı ve hisse senedi piyasası işlem hacmi gibi belirli değişkenlerin söz konusu NAV değerlerinin hareketinde önemli bir etkiye sahipken, diğer değişkenlerin yatırım fonunun NAV değerleri üzerinde fazla bir etkiye sahip olmadığı sonucuna ulaşmışlardır[4].

Wang\&Huang (2010) yatırım fonları üzerinde yaptıkları çalışmada yapay sinir sınıflandırıcısı ve bu modelin geri yayılım algoritmasını kullanarak yatırım fonlarının performansını belirlemeye çalışmışlardır. Araştırmacılar, Tayvan'da faaliyet gösteren yatırım fonları üzerine yaptıkları bu araștırmada Taiwan Economic Journal veri tabanından kullandıkları verileri 1995-1996, 1997-1998 ve 1999-2000 tarihleri arasında üç farklı döneme ayırmışlardır. Çalışmada tasarlanan hızlı uyarlanabilir sinir ağı sinıflandırıcısı (FANNC) bir geri yayılım sinir ağ (BPN) modeliyle karşılaştırılmaktadır. FANNC yaklaşımı, yatırım fonu performansını değerlendirmek için BPN yaklaşımından çok daha az zaman gerektirmekte ve daha üstündür. Sonuçlar hem sınıflandırma problemleri hem de tahmin problemleri için FANNC'ın büyük hacimli veri ve rutin güncellemeler gerektiren finansal uygulamalar için daha ideal olduğunu göstermektedir [5].

Chen ve diğerlerinin Tayvan'da 2000-2010 dönemini kapsayan 100 adet hisse senedi ağırlıklı yatırım fonları üzerine yapmış oldukları çalışmada yapay sinir ağları metodu ile bu yatırım fonlarının NAV değerlerini tahmin başarısını ölçmüşlerdir. Elde edilen ampirik sonuçlara göre yapay sinir ağı modellemesinin sadece performansı yüksek fonu bulmakla kalmayıp en iyi tahmini de bulduğu sonucuna ulaşmışlardır. Özellikle hisse senedi ağırlıklı yatırım fonlarına kısa ve orta vadeli yatırım yapmayı, yatırımcılar için yapay sinir analizi modellerinin yararlı olacağ bulgusunu elde etmişlerdir [6].

Akel ve Karacameydan'ın 2012 yılında yayımlanan çalışmalarında, yapay sinir ağları metodu kullanılarak Türkiye'de faaliyet gösteren yatırım fonlarının NAV değerlerini tahmin etmeye yönelik bir model geliştirilmiştir. Çalışmada Ocak 2001 ve Aralık 2008 dönemini kapsayan 19 adet A tipi yatırım fonu ve 19 adet B tipi yatırım fonunun NAV değerleri bağımlı değişken olarak kullanılmış, bağımsız değişken olarak da tahvil faiz oran1, Dolar/TL kuru, sanayi üretim endeksi, M2 para arz1, Toptan Eşya Fiyat Endeksi ve BIST 100 endeksi kullanılmıştır. B tipi yatırım fonlarının A tipi yatırım fonlarına göre daha başarılı tahmine olanak sağladığ sonucuna ulaşmışlardır. Bunun yanında A tipi yatırım fonlarının alt türü olan değişken, hisse senedi ve endeks yatırım fonları üzerinde de başarılı tahmin sonuçları elde etmişlerdir [7] .

Onocak ve Koç'un Türkiye'deki 6 adet hisse senedi emeklilik yatırım fonlarına yönelik yapmış oldukları araştırmada yapay sinir ağı kullanılarak bu emeklilik fonlarının hisse fiyatlarının tahmini yapılmaya 
çalışılmıştır. Ocak 2003- Ekim 2017 yıllarına ait bağımsız değişken olarak Euro kuru, dolar kuru, cumhuriyet altını satış fiyatı, BİST 100 endeksi kapanış fiyatı, bankalarca açılan TL mevduatlara uygulanan ağırlıklı ortalama faiz oranı ve tüketici fiyat endeksi kullanılmış bağımlı değişken olarak bu emeklilik yatırım fonlarının hisse senedi fiyatları kullanılmıştır. Tasarladıkları yapay sinir ağı modeli ile aylık verilerin \% 70'inin eğitim, \% 10'unun doğrulama ve \% 20'sinin test için kullanılmışlar ve her bir emeklilik yatırım fonu için yüksek bir tahmin başarı oranı elde etmişlerdir [8].

\section{METOT (METHOD)}

Yapay zekâ teknolojisinde önemli bir yeri olan YSA tekniği insan beyninin çalışma şeklini taklit eden bir çalışma yapısına sahiptir. YSA tekniği çok sayıda değişkenle çalışarak bunları öğrenme ve genelleme yapabilme yeteneğine sahiptir [9, 10]. YSA, gerçek dünyadaki karmaşık sistemlerde doğrusal olmayan girdi çıktı arasındaki ilişkilerini temsil etmektedir ve bunu örneklerle öğrenebilir [11, 12].

Regresyon analizi iki veya daha çok değişken arasındaki bağıntıyı tespit etmek ve modellemek için kullanılmaktadır [13]. Regresyon analizinde değişkenler bağımlı ve bağımsız değişken olmak üzere ikiye ayrılır. Bağımlı değişken, bağımsız değişken(ler) tarafından açıklanmaya çalışılan değişkendir [14]. Regresyon analizi bir bağıml bir bağımsız değişken arasında oluyorsa basit regresyon analizi, birden çok bağımsız değişken ile bağımlı değişken arasında oluyorsa çoklu regresyon analizi olarak ifade edilir [13].

\section{1. Çok Katmanlı Algılayıcı (Multilayer Perceptron)}

Çok katmanlı algılayıcı ağlar (ÇKA), giriş ve çıkış katmanları arasında en az bir katman kullanan yapay bir sinir ağı türüdür. Tek katmanlı algılayıcının aksine, ÇKA'lar doğrusal olmayan sorunları çözebilir, bu nedenle yaygın kullanımda en popüler yapay sinir ağı türüdür [15] $\mathrm{Bu}$ ÇKA mimari yapısında giriş katmanından, çıkış katmanından ve k adet gizli katman ve her gizli katmanda 2 adet nörondan oluşmaktadır [16]. Giriş katmanı her bir bağımsız değişkene karşılık gelen çok sayıda nörondan oluşmaktadır. Gizli katman, değişkenler arasındaki doğrusal olmayan ilişkilerin yakalanmasını sağlamaktadır. Çıkış katmanı da tahmin edilen sınıflandırmaya veya öneriye karşılık gelmektedir [17]. ÇKA metodu ileri yönde bir iletim gerçekleştirirken aynı zamanda hatayı en aza indirgemek için geri yayılım algoritması kullanmaktadır. İleri iletim, ağa uygulanan girişin bir önceki katmandan bir sonraki katmana sırasıyla ilerleyerek çıkış katmanına ulaşmasıdır. Hata sinyali, giriş sinyalinin çıkış katmanına ulaşan değeri ile istenen değeri arasındaki farka denilmektedir. Hata sinyali, çıkış katmanından giriş katmanına doğru ilerler ve ağırlık değerleri güncellenerek hata değerinin en aza indirgenmesini amaçlamaktadır [18]. Her gizli birimin, genel olarak doğrusal olmayan ve tüm gizli birimler için aynı olan bir etkinleştirme işlevi vardır. Gizli bir birimin çıktısı, aktivasyon fonksiyonunun, önceki katmandan gelen ağırlıklı sinyallerin ve ayrı bir sapmanın toplamına uygulanmasıyla belirlenmektedir [19].

Şekil 2'de bir giriş, iki gizli katman ve bir çıkış katmanından oluşan çok katmanlı algılayıcı ağı görülmektedir.

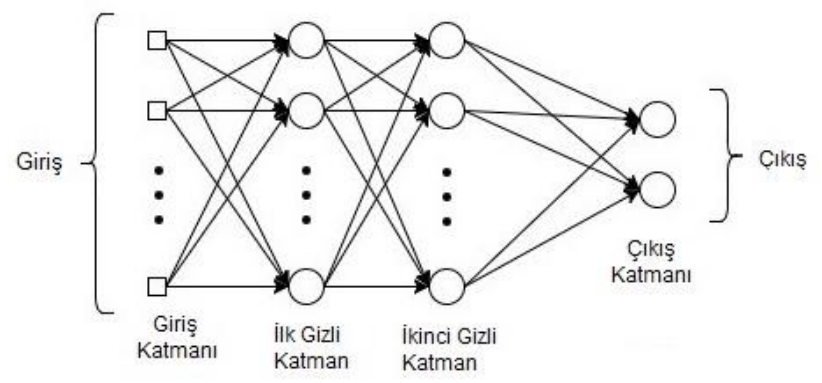

Şekil 2. Çok katmanlı algılayıcı (Multilayer perceptron)

Çok katmanlı algılayıcıların çalışma yapısı ağın çıkışının hesaplandığı ileriye doğru hesaplama ve ağırlıkların güncellendiği geriye doğru hesaplama olmak üzere iki aşamadan oluşmaktadır [20]. İleri doğru hesaplamanın temel amacı verilen giriş değerleri için çıkış değerinin tahmin edilmesi ve hedeflenen değer kullanılarak hatanın hesaplanmasıdır [21].

Giriş hücrelerindeki bilgiler ara katman hücrelerine aktarılırken ilgili ağırlıklar ile çarpılmakta ve ağırlıklı toplam fonksiyonuna göre her ara katman hücresinin NET girdisi hesaplanmaktadır:

$$
N E T_{p}=\sum_{i} w_{i p} x_{i}
$$

Burada $\mathrm{NET}_{\mathrm{p}}$ ara katmanın $\mathrm{p}$. hücresine olan girdi; $\mathrm{w}_{\mathrm{ip}}$ giriş katmanının i. hücresini, ara katmanın p. hücresine bağlayan ağırlık; $x_{i}$ giriş katmanındaki i. hücresinin çıkışını temsil etmektedir. Bulunan NET girdi, bir aktivasyon fonksiyonundan geçirilerek, ara katman hücrelerinin çıkışı bulunmaktadır.

$$
F_{p}=f\left(N E T_{p}\right)
$$

Burada $F_{p}$ ara katmanın p. hücresinin aktivasyon fonksiyonunu göstermektedir. Kullanılacak aktivasyon fonksiyonun türevlenebilir olması şarttır.

$\mathrm{Bu}$ aşamadan sonra hedef değer ile çıkış hücresinde bulunan değeri kullanarak hata hesaplaması yapılmaktadır. Hata hesaplamas1:

$$
\varepsilon_{p}=\left(T_{p}\right)-\left(F_{p}\right)
$$

$\varepsilon_{\mathrm{p}}$ yapılan hata; $\mathrm{T}_{\mathrm{p}}$ hedeflenen çıkış değeri; $\mathrm{F}_{\mathrm{p}} \mathrm{p}$. Hücrenin hesaplanan değerini göstermektedir.

İkinci aşama olan geriye doğru hesaplamada ağırlıklar güncellenerek hata oranı en aza indirgenmesi amaçlanır. Bunun için hata değerleri geriye doğru yayılır ve ağırlıklara 
ait güncelleme kuralları oluşturulur. Hata, öncelikli olarak çıkış katmanı ile ara katman arasındaki ağırlık değerleri; sonra ara katman ile giriş katmanı arasındaki ağırlık değerleri hesaplatılarak geriye doğru ilerler [21].

\section{2. Çoklu Doğrusal Regresyon (Multiple Linear Regression)}

Çoklu doğrusal regresyonun (ÇDR) temel amacı birden fazla bağımsız değişken ile tek bir bağımlı değişken arasındaki ilişkiyi ortaya koyarak tahminlerde bulunmak ve tahminleri kullanarak değişkenler arasında matematiksel bir model oluşturmaktır [22].

Bağımlı değişkende meydana gelen değişmenin daha fazla bağımsız değişken ile ilişkili olduğu durumlarda çoklu doğrusal regresyon modeli kullanılabilmektedir [23, 24]. Bağımlı ve bağımsız değişkenler arasındaki ilişki doğrusal kabul ediliyorsa çoklu doğrusal regresyon; doğrusal ifade edilmiyorsa doğrusal olmayan çoklu doğrusal regresyon modeli ile ifade edilmektedir [25].

N sayıda bağımsız değişkenin olduğu çoklu doğrusal regresyon modeli [26]:

$$
Y=\beta_{0}+\beta_{1} X_{1}+\beta_{2} X_{2}+\cdots+\beta_{n} X_{n}+\varepsilon
$$

$\mathrm{Bu}$ modelde $\mathrm{Y}$ bağımlı değişkeni, $\mathrm{X}_{1}, \mathrm{X}_{2}, \ldots, \mathrm{X}_{\mathrm{n}}$ bağımsız değişkenleri ve $\beta_{0}, \beta_{1}, \ldots \ldots, \beta_{n}$ bilinmeyen parametreleri, $\varepsilon$ ise hata terimini temsil etmektedir.

Çoklu doğrusal regresyon modelleri bazı varsayımlara dayanmaktadır. Bunlar $\varepsilon$ hata terim ile bağımsız değişkenler arasındaki ilişki, bağımsız değişkenlerin kendi aralarındaki ilişki ve $\varepsilon$ hata teriminin dağılımı hakkındadır. Tahminlerin sağlıklı sonuçlar verebilmesi bu varsayımların sağlanmasıyla mümkün olacaktır. Bu varsayımlar kısaca, varyansı sabit, hata terimleri ortalaması sıfır, normal dağılıma sahip stokastik bir değişkindir. Hata terimleri arasında bir ilişki yani otokorelasyon yoktur. Ayrıca bir başka varsayım ise bağımsız değişkenler arasında bir ilişki yani çoklu bağıntı olmamalıdır [27].

\section{UYGULAMA (IMPLEMENTATION)}

$\mathrm{Bu}$ çalışmada bağımlı değişkenler olan 12 bireysel emeklilik fonunun getiri tahmini, 12 bağımsız değişken üzerinden tahmin edilmeye çalışılmıştır. Tahminler için çok katmanlı algılayıcı ağlar (ÇKA) ve çoklu doğrusal regresyon (ÇDR) yöntemleri kullanılmıştır. Bağımlı değişken olarak aşağıda bulunan emeklilik yatırım fonlarının net varlık değerleri (NAV) kullanılmıştır.

- Vakıf Emeklilik Hisse Senedi EYF

- NN Hayat Emeklilik Hisse Senedi EYF

- NN Hayat Emeklilik Karma EYF

- Garanti Emeklilik Hisse Senedi EYF

- $\quad$ FİBA Emeklilik Hisse Senedi EYF

- Allianz Hayat Dengeli Değişken EYF

- Allianz Yaşam Hisse Senedi EYF

- AHE Birinci Değişken EYF

- AHE Atak Değişken EYF
- $\quad$ AHE Hisse Senedi EYF

- AVIVASA Hisse Senedi Grup EYF

- AVIVASA Dinamik Değişken EYF

Çalışmada bağımsız değişken olarak 2005 Aralık ile 2020 Ocak tarihleri arasındaki aşağıdaki bağımsız değişkenler gösterilmiştir. Araştırmaya konu olan emeklilik yatırım fonları hem yönetim stratejileri hem de yasal olarak portföylerinde yüksek oranda hisse senetleri yatırımı yapmaktadırlar. Bu fonların portföy ağırlığını oluşturan hisse senetleri yatırımları yanında portföyü oluşturan diğer menkul kıymet/para piyasası yatırımlarını da temel makro ekonomik göstergeler ile piyasa verilerinden direkt olarak etkilenmektedir. Bu etkileşim, emeklilik yatırım fonlarının net varlık değerlerini değiştirmektedir. Çalışmada, bu nedenden ötürü literatürde önceki çalışmaların paralelinde bir ülkenin hisse senedi piyasalarını etkilemekte olan bu makroekonomik göstergeler ile piyasa verileri bağımsız değişken olarak seçilmiştir. Bu bağımsız değişkenlerden BIST 100, BIST 30, Sanayi Üretim Endeksi, İhracat göstergelerinin artışları emeklilik yatırım fonlarının portföylerindeki hisse senedi ağırlıklarını artıracağı, ham petrol fiyatı, TÜFE, 1 aylık mevduat faizi oranı, altın fiyatı, iki yıllık gösterge tahvil faiz oranı, işsizlik oranı, ve Türk Lirası cinsinden dolar-avro değerlerindeki artışların ise portföylerdeki hisse senedi ağırlıklarını azaltılacağı ve buna karşılık portföyü oluşturan diğer menkul kıymet/para piyasası yatırımlarını artıracağı beklenmektedir. $\mathrm{Bu}$ etkileşim emeklilik fonlarının farklı portföy yönetim stratejilerine göre net varlık değerlerindeki büyümeyi hızlandırmakta ya da yavaşlatmaktadır. Sonuçta bu fonları satın alarak gelecek kurgulayan yatırımcıların getirilerini değiştirmektedir. Bağımsız değişkenler literatürdeki benzer çalışmalar temel alınarak seçilmiştir. Bu seçimi yaparken Türkiye'nin makro ekonomik yapısı ve menkul kıymet piyasaları göstergeleri gözetilmiştir.

- Ham petrol

- Tüfe

- BIST100

- BIST30

- Sanayi üretim

- $1 \mathrm{M}$

- TL/ons

- İhracat

- USD/TRY

- EUR/TRY

- 2YBOND

- İssizlik

Yukarıdaki bağımlı ve bağımsız değişkenler ile ilgili dönemi kapsayan her bir emeklilik yatırım fonu için 170 adet veri kullanılmıştır.

Yapılan tahminlerin başarısını ölçmek için başarı tahmin oran1, determinasyon katsay1s1 $\left(\mathrm{R}_{2}\right)$, hata kareleri ortalaması (Mean Squared Error - MSE), ortalama hata karelerinin karakökü (Root Mean Squared Error -RMSE), ortalama mutlak hata (Mean Absolute Error -MAE), ortalama mutlak yüzde hata (Mean Absolute Percentage Error - MAPE) yöntemleri kullanılmıştır. Başarı oranı \%5 
tolerans ile başarılı tahmin edilen verilerin, toplam verilere oranını göstermektedir. Diğer yöntemlere ait denklemler aşağıda verilmiştir.

$$
\begin{aligned}
& R^{2}=1-\frac{\sum\left(Y_{i}-Y_{i}^{*}\right)^{2}}{\sum\left(Y_{i}-Y_{\text {ave }}\right)^{2}} \\
& M S E=\frac{1}{n} \sum_{i=1}^{n}\left(Y_{i}-Y_{i}^{*}\right)^{2} \\
& R M S E=\sqrt{\frac{1}{n} \sum_{i=1}^{n}\left|\frac{Y_{i}-Y_{i}^{*}}{Y_{i}}\right|^{2}} \\
& M A E=\frac{\sum_{i=1}^{n}\left|Y_{i}-Y_{i}^{*}\right|}{n} \\
& M A P E=\frac{\sum_{i=1}^{n}\left|\frac{Y_{i}-Y_{i}^{*}}{Y_{i}}\right|}{n} \cdot 100
\end{aligned}
$$

Burada $Y_{i}$ gözlem değeri, $Y_{i}^{*}$ tahmin edilen değeri, $Y_{\text {ave }}$ gözlem değerlerinin ortalamasını temsil etmektedir.

\section{1. Çok Katmanlı Algılayıcı Yöntemi (Multilayer Perceptron Method)}

Çok Katmanlı Algılayıcı yönteminde veriler excel ortamında alınmakta ve ondalık ölçekleme (decimal scaling) yöntemi kullanılarak 0 ile 1 arasında normalize edilmektedir. $\mathrm{Bu}$ yöntemde verilerin değerlerinin ondalık noktasını hareket ettirerek normalleştirme işleme gerçekleştirilir. Verileri bu teknikle normalleştirmek için, verilerin her bir değeri verinin maksimum mutlak değerine bölünmektedir. Verinin veri değeri $\mathrm{v}_{\mathrm{i}}$, aşağıdaki formül kullanılarak $\mathrm{v}_{\mathrm{i}}^{\prime}$ olarak normalleştirilir.

$$
v_{i}^{\prime}=\frac{v_{i}}{10^{j}}
$$

Burada j, $\max \left(\left|\mathrm{v}_{\mathrm{i}}\right|\right)<1$ olacak şekilde en küçük tamsayıdır. Verilerin \%70'i eğitim, \%30'u test amaçlı olmak üzere rastgele seçilerek ÇKA ağına aktarılmaktadır. ÇKA ağında 10.000 iterasyon, 2 gizli katman ve her gizli katmanda 5 nöron olacak şekilde modellenmektedir. Modelde hata fonksiyonunun davranışına göre ağırlık değerlerinin güncellemelerinin yapıldı̆̆ kullanmaktadır.

Model oluştururken kullanılan parametrelerin alacağ değerler her bir bağımlı değişken için en yüksek performansı gösterecek şekilde farklı değerler verilerek test edilmiş ve ideal değerler seçilmiştir. Oluşturulan ÇKA ağ modeli Şekil 3'te görülmektedir.

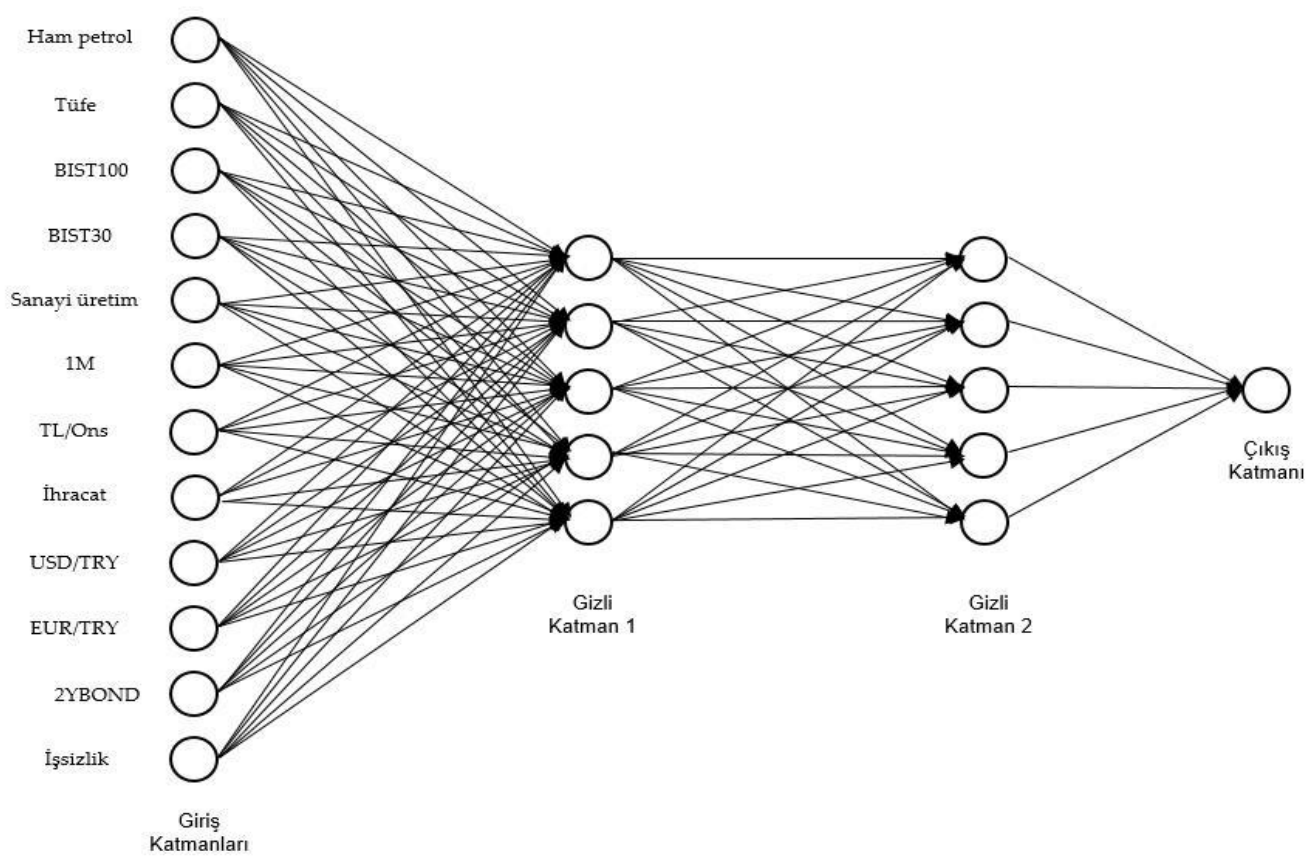

Şekil 3. Çok katmanlı algılayııı modeli (Multilayer perceptron model)

Her bir emeklilik yatırım fonu için kullanılan 170 adet verinin \%70'i (118 adet) eğitim amaçl1; \%30'u (52 adet) test amaçlı olarak kullanılmıştır. Knime programı kullanılarak oluşturulan ÇKA yöntemi Şekil 4'te görülmektedir. Tablo 2'de ÇKA yöntemine göre her bir bağımsız değişkenin performansları (test sonuçları) görülmektedir.
ÇKA yöntemine göre emeklilik fonlarının tahmininde başarı oranı en yüksek $\% 92,31$; en düşük $\% 57,69$; ortalama başarı oranı \%77,40 olmaktadır. Çalışmada ortalama MSE değeri 0 olduğu için bu ideal değerdedir. RMSE değerinin ekonometrik olarak sıfıra yakın olması istenmekte; bu çalışmada 0,001-0,027 aralığında olup; ortalama 0,011 ile istenen değere çok yakın olduğu görülmektedir. MAE ve MAPE içinde en küçük değere sahip değerler istenmekte; bu çalışmada da sırasıyla 
0,006 ve 0,076 ile istenen değerlere çok yakın değerler olduğu görülmektedir [28-30].

\section{2. Çoklu Doğrusal Regresyon Yöntemi (Multiple Linear Regression Method)}

ÇDR yönteminde de girişte 12 bağımsız değişken ve her bağımsız değişkenin değerini hesaplarken 170 veri kullanılmıştır. Knime programı kullanılarak oluşturulan çoklu doğrusal regresyon yöntemi Şekil 5'te görülmektedir. Çalışmamızdaki her bir bağımlı değişken için analizler ayrı ayrı yapılmaktadır. Tablo 3'te ÇKA yöntemine göre her bir bağımsız değişkenin performansları görülmektedir.

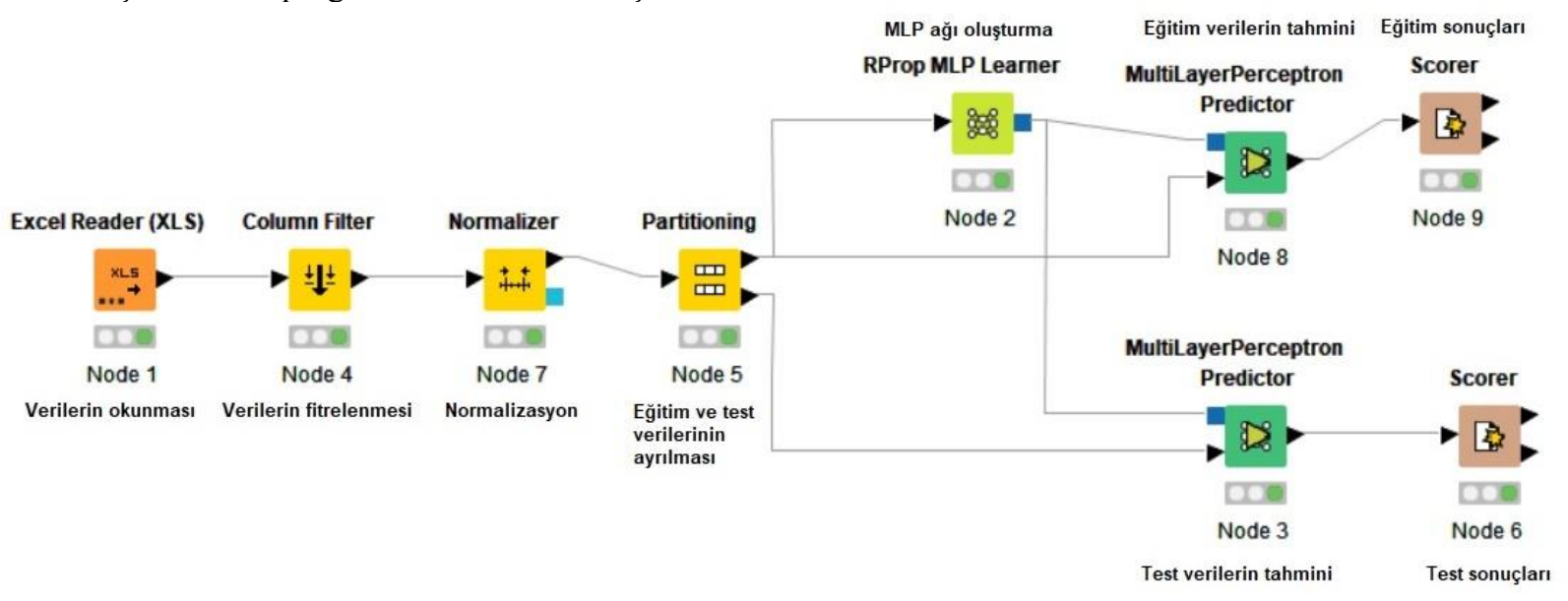

Şekil 4. Knime programında çok katmanlı algılayıcı uygulaması (Multilayer Perceptron application in Knime program)

Tablo 2. Çok katmanlı algılayıcı yönteminin test verilerinin istatiksel analiz sonuçları

\begin{tabular}{|l|c|c|c|c|c|c|}
\hline \multicolumn{1}{|c|}{ Bağımlı Değişkenler } & Başarı oranı* $\mathbf{( \% )}$ & $\mathbf{R 2}$ & MSE & RMSE & MAE & MAPE \\
\hline Vakıf Emeklilik Hisse Senedi EYF & 76,92 & 0,974 & 0 & 0,015 & 0,008 & 0,053 \\
\hline NN Hayat Emeklilik Hisse Senedi EYF & 71,15 & 0,993 & 0,003 & 0,004 & 0 & 0,064 \\
\hline NN Hayat Emeklilik Karma EYF & 86,54 & 0,997 & 0 & 0,005 & 0,004 & 0,042 \\
\hline Garanti Emeklilik Hisse Senedi EYF & 78,85 & 0,930 & 0,001 & 0,027 & 0,011 & 0,1 \\
\hline FïBA Emeklilik Hisse Senedi EYF & 65,38 & 0,965 & 0,001 & 0,034 & 0,020 & 0,064 \\
\hline Allianz Hayat Dengeli Değişken EYF & 78,85 & 0,999 & 0 & 0,002 & 0,002 & 0,05 \\
\hline Allianz Yaşam Hisse Senedi EYF & 92,31 & 0,993 & 0 & 0,011 & 0,008 & 0,072 \\
\hline AHE Birinci Değişken EYF & 57,69 & 0,994 & 0 & 0,015 & 0,007 & 0,159 \\
\hline AHE Atak Değişken EYF & 88,46 & 0,998 & 0 & 0,001 & 0,001 & 0,098 \\
\hline AHE Hisse Senedi EYF & 80,77 & 0,997 & 0 & 0,012 & 0,009 & 0,076 \\
\hline AVIVASA Hisse Senedi Grup EYF & 82,69 & 0,998 & 0 & 0,004 & 0,003 & 0,054 \\
\hline AVIVASA Dinamik Değişken EYF & 69,23 & 0,998 & 0 & 0,004 & 0,003 & 0,085 \\
\hline Ortalama & 77,40 & 0,986 & 0,000 & 0,011 & 0,006 & 0,076 \\
\hline
\end{tabular}

* Başarı oranı: $\pm \% 5$ tolerans değeri ile tüm test veriler içerisinden başarı ile tahmin edilenlerin yüzdesi

ÇDR yöntemine göre emeklilik fonlarının tahmininde başarı oranı en yüksek $\% 57,69$; en düşük $\% 32,69$; ortalama başarı oranı \% 44,54 olmaktadır. Çalışmada ortalama MSE değeri 0'a çok yakın olduğu için ideal değerdedir. RMSE değerinin sıfıra yakın olması istenmekte; bu çalışmada 0,005-0,088 aralığında olup; ortalama 0,024 ile istenen değere çok yakın olduğu görülmektedir. MAE ve MAPE içinde en küçük değere sahip değerler istenmekte; bu çalışmada da sırasıyla 0,018 ve 0,4 ile istenen değerlere çok yakın değerler olduğu görülmektedir.

\section{SONUÇLAR (CONCLUSION)}

$\mathrm{Bu}$ çalışmada bireysel emeklilik fonlarının getirilerini tahmin etmek için çok katmanlı algılayıcı (ÇKA) ve çoklu doğrusal regresyon (ÇR) yöntemleri kullanılmıștır. Bağımlı değişken olarak her bir fonun net varlık değerini (NAV) tahmin etmek için 12 bağımsız değişken kullanılmış ve modeller bu şekilde oluşturulmuştur. ÇKA modelinde 12 giriş nöronu, 2 gizli katman ve her gizli katmanda 5 nöron, bağımlı değişkene karșılık gelen bir çıkış nöronu olan geri beslemeli ağ tasarlanmıştır. Ağın parametreleri en iyi performans gösterecek şekilde ayarlanmıştır. $\mathrm{Bu}$ tahminler geliştirilen çoklu doğrusal regresyon yöntemi ile elde edilen değerler ile karşılaştırılmıştır. İki modelin verimliliğini ve hata performansını ölçmek için istatistiksel tekniklerden faydalanılmıştır. 
Sonuçlar, ÇKA yaklaşımının emeklilik fonu performansını tahmin etmek için çoklu doğrusal modellerden daha üstün olduğunu göstermektedir. Başarı oranı karşılaştırmasında ÇKA yönteminin ÇDR'ye göre daha başarılı olduğu görülmüştür. R2, RMSE, MAE ve MAPE analizlerine göre yakın değerler olmakla birlikte ÇKA yönteminin daha az hata ile tahmin yaptığg görülmektedir. Elde edilen bu sonuç literatürdeki çalışmalarla benzerlikler taşımaktadır.

Chiang ve diğerleri (1996) ile Indro ve diğerleri (1999) yapmış olduğu çalışmalarda araştırma sonuçlarımıza benzer şekilde ÇKA'nın ÇDR'ye göre daha başarılı olduğu sonucunu ulaşmışlardır. Aynı zamanda Ray ve Vani (2004), Akel ve Karacameydan (2012), Onocak ve Koç (2018) çeşitli menkul kıymetlerin NAV'ını tahmin etmede çalışmadaki modelde kullanılan benzer makro ekonomik ve piyasa göstergelerini bağımsız değişkenler kullanmışlar ve benzer şekilde ÇKA ile yüksek tahmin başarısı oranına ulaşmışlardır.

Seçilen emeklilik fonlarının özellikleri ve seçilen bağımsız değişkenlerin niteliğinin ve niceliğinin literatüre göre geliştirilmesi, bu sonucun çıkmasında etkili olmaktadır.
Çalışmanın yapıldığı dönem aralığında meydana gelen ve Türkiye'ye etkileri 2008 yılının ortalarında hissettirmeye başlayan Amerika Birleşik Devletleri kaynaklı mortgage krizi ve 2011 yılında başlayan Avrupa Birliği kaynaklı ekonomik krizin meydana getirdiği dönemsel ekonomik şoklara rağmen tasarlanan yapay sinir ağı modeli oldukça yüksek başarı tahmin oranlarını yakaladığı söylenebilir. Bu yüzden de ileriki dönemde yapılacak bilimsel çalışmalar için yapay sinir ağı tekniği karşılaştırmalı model çalışmalarında kullanılabilir.

Çalışmada emeklilik yatırım fonlarının reel getirileri ile tahmin başarı oranları arasında anlamlı bir ilişki bulunmamaktadir.

$\mathrm{Bu}$ çalışmadan elde edilen sonuçlara göre atak yatırım fon yöneticilerinin ÇKA yöntemini kullanarak yönettikleri fonların başarısının sürdürülebilir hale getirebileceği görülmektedir.

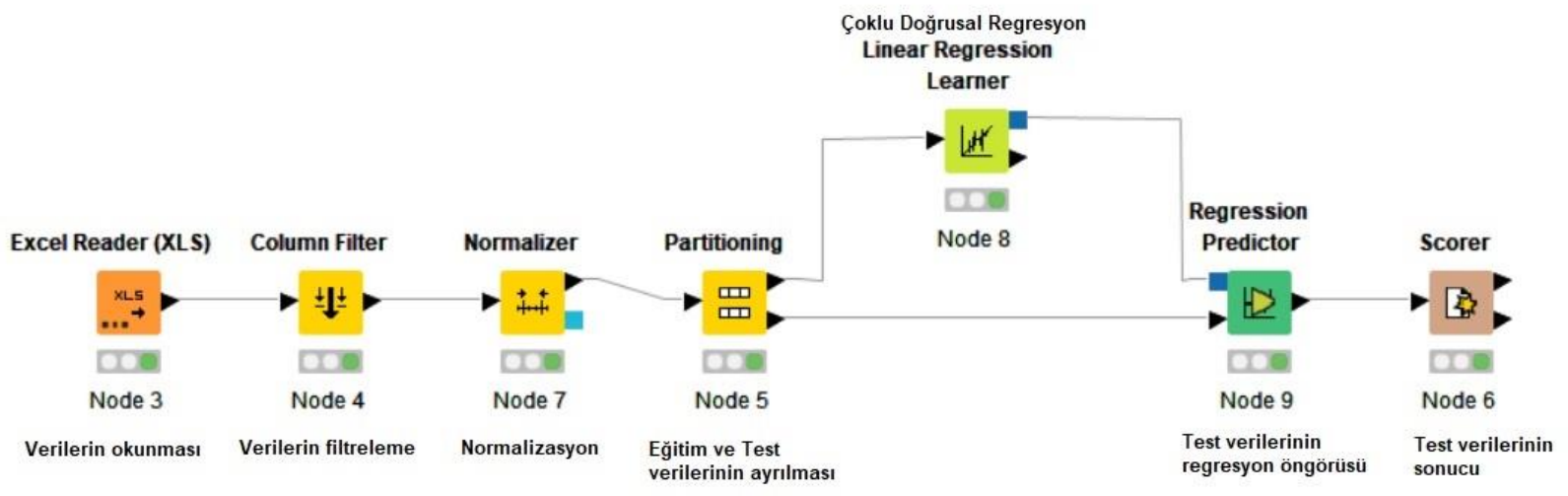

Şekil 5. Çoklu doğrusal regresyon modeli (Multiple linear regression model)

Tablo 3. Çoklu doğrusal regresyon yönteminin test verilerinin istatiksel analiz sonuçları (Statistical analysis of multiple linear regression)

\begin{tabular}{|l|c|c|c|c|c|c|}
\hline \multicolumn{1}{|c|}{ Bağımlı Değişkenler } & Başarı oranı* (\%) & R2 & MSE & RMSE & MAE & MAPE \\
\hline Vakıf Emeklilik Hisse Senedi EYF & 40,38 & 0,971 & 0 & 0,016 & 0,012 & 0,237 \\
\hline NN Hayat Emeklilik Hisse Senedi EYF & 42,30 & 0,902 & 0 & 0,015 & 0,009 & 0,214 \\
\hline NN Hayat Emeklilik Karma EYF & 48,07 & 0,906 & 0,001 & 0,027 & 0,018 & 0,18 \\
\hline Garanti Emeklilik Hisse Senedi EYF & 48,07 & 0,981 & 0 & 0,014 & 0,01 & 0,218 \\
\hline FïBA Emeklilik Hisse Senedi EYF & 38,46 & 0,856 & 0,008 & 0,088 & 0,07 & 0,23 \\
\hline Allianz Hayat Dengeli Değişken EYF & 48,07 & 0,982 & 0 & 0,012 & 0,01 & 0,369 \\
\hline Allianz Yaşam Hisse Senedi EYF & 50,00 & 0,971 & 0,001 & 0,023 & 0,018 & 0,223 \\
\hline AHE Birinci Değişken EYF & 36,50 & 0,982 & 0,001 & 0,024 & 0,02 & 1,355 \\
\hline AHE Atak Değişken EYF & 57,69 & 0,973 & 0 & 0,005 & 0,004 & 0,185 \\
\hline AHE Hisse Senedi EYF & 55,76 & 0,981 & 0,001 & 0,028 & 0,024 & 0,546 \\
\hline AVIVASA Hisse Senedi Grup EYF & 32,69 & 0,958 & 0 & 0,017 & 0,012 & 0,348 \\
\hline AVIVASA Dinamik Değişken EYF & 36,53 & 0,974 & 0 & 0,015 & 0,012 & 0,694 \\
\hline Ortalama & 44,54 & 0,953 & 0,001 & 0,024 & 0,018 & 0,400 \\
\hline
\end{tabular}

* Başarı oranı: $\pm \% 5$ tolerans değeri ile tüm test veriler içerisinden başarı ile tahmin edilenlerin yüzdesi

Özellikle Türkiye gibi gelişmekte olan ekonomilerde sermaye piyasalarındaki volatilitenin çok yüksek olduğu ve bu piyasalara yatırım yapan atak emeklilik yatırım fonlarının sürdürülebilir bir başarı yakalaması için ÇKA yöntemi ile modeller kurması başarılarını daha da artırabilir. Bu başarının sürdürülebilir olması aynı zamanda Türk sermaye piyasalarının derinleşmesine ve kurumsallaşmasına katkı verecektir. 


\section{KAYNAKLAR (REFERENCES)}

[1] Internet: Emeklilik Gözetim Merkezi, BES Özet Verileri. https://www.egm.org.tr/bilgi-merkezi/istatistikler/, 21.03.2020.

[2] W.C. Chiang, T. L. Urban, G. W. Baldridge, "A neural network approach to mutual fund net asset value forecasting", Omega, 24(2), 205-215, 1996.

[3] D. C. Indro, C. Jiang, B. Patuwo, G. Zhang, "Predicting mutual fund performance using artificial neural networks", Omega, 27(3), 373-380, 1999

[4] P. Ray, V. Vina, "Neural network models for forecasting mutua fund net asset value", 8th Capital Markets Conference, Indian, $1-18,2004$.

[5] K. Wang, S. Huang, "Using fast adaptive neural network classifier for mutual fund performance evaluation", Expert Systems with Applications, 37(8), 6007-6011, 2010.

[6] C.C. Chen, A.P. Chen, P.Y. Yeh, "Modeling and simulation of the open-end equity mutual fund market in Taiwan by using selforganizing map", Simulation Modelling Practice and Theory, 36, 60-73, 2013.

[7] V. Akel, F. Karacameydan, "Yatırım Fonları Net Varlık Değerlerinin Yapay Sinir Ağları Yöntemiyle Tahmin Edilmesi", Anadolu University Journal of Social Sciences, 12(2), 87-105, 2012.

[8] D. Onocak, S. Koç, "Yapay Sinir Ağları ile Emeklilik Yatırım Fonu Hisse Senedi Fiyatlarının Tahmini", Finans Ekonomi ve Sosyal Araştırmalar Dergisi (FESA), 3(3), 590-600,2018.

[9] B. Ataseven, "Yapay Sinir Ağları ile Öngörü Modellemesi," Öneri Dergisi, 10(39), 101-115, 2013.

[10] T. Ş. Yapraklı, H. Erdal, "Firma başarısızlığg tahminlemesi: Makine öğrenmesine dayalı bir uygulama", International Journal of Informatics Technologies, 9(1), 21-31, 2016.

[11] A. M. Kalteh, R. Berndtsson, "Interpolating monthly precipitation by self-organizing map (SOM) and multilayer perceptron (MLP)", Hydrological Sciences Journal, 52(2), 305-317, 2007.

[12] H. Özkişi, M. Topaloğlu, "Fotovoltaik hücrenin verimliliğinin yapay sinir ağı ile tahmini", Bilişim Teknolojileri Dergisi, 10(3), 247-253, 2017

[13] M. Çakıcı, A. Oğuzhan, T. Özdil, İstatistik. Ekin Yayınları, Bursa 2015 .

[14] R. Karabulut, K. Şeker, "Belirlenmiş Değişkenlerin Vergi Gelirleri Üzerindeki Etkisi: Çoklu Doğrusal Regresyon Analizi", Süleyman Demirel Üniversitesi İktisadi ve İdari Bilimler Fakültesi Dergisi, 23(3), 1049-1070, 2018.
[15] V. Kargi, "A comparison of artificial neural networks and multiple linear regression models as in predictors of fabric weft defects", Tekstil ve Konfeksiyon, 24, 309-316, 2014.

[16] A. K. Dhamija, V. K. Bhalla, "Exchange rate forecasting: comparison of various architectures of neural networks", Neural Computing and Applications, 20(3), 355-363, 2011.

[17] E. Baranoff, T. Sager, T. Shively, "A Semiparametric Stochastic Spline Model as a Managerial Tool for Potential Insolvency", The Journal of Risk and Insurance, 67, 369-396, 2000.

[18] G. Kumaşoğlu, B. Bolat, "Yapay Sinir Ağlarıyla Müzikal Tür Tanıma," Elektrik-Elektronik Bilgisayar Sempozyumu (FEEB 2011), Elazı̆̆g, Türkiye, 61-64, 5-7 Ekim 2011.

[19] S. Trenn, "Multilayer Perceptrons: Approximation Order and Necessary Number of Hidden Units", IEEE Transactions on Neural Networks, 19(5), 836-844, 2008.

[20] G. İclal, "Çok Katmanlı Algılayıcı Yapay Sinir Ağı ile Lineer Diferansiyel Denklem Sisteminin Çözümü", 18. Akademik Bilis, im Konferansı, Aydın, 3-5 Şubat 2016.

[21] M. O. Öğücü, Yapay Sinir Ağları İle Sistem Tanıma, Doktora Tezi, İstanbul Teknik Üniversitesi, Fen Bilimleri Enstitüsü, 2006.

[22] M. Bahçecitapar, S. Aktaş Altunay, "Çoklu doğrusal bağlantı durumunda doğrusal karma modelin kullanımı ve bir uygulama", Sakarya Üniversitesi Fen Bilimleri Enstitüsü Dergisi, 21(6), 13491359, 2017.

[23] A. Tunahan, "Makroekonomik Faktörler ve Banka Kredilerinin Enflasyon Üzerindeki Etkisi: Türkiye Örneği", Finans Ekonomi ve Sosyal Araştırmalar Dergisi, 5(1), 98-107, 2020.

[24] N. Bekiroğlu, R. Konyalığlu, D. Karahan, "Çoklu doğrusal regresyon sonuçlarının Jackknife tekniği ile tekrarlanabilirliğinin değerlendirilmesi", Marmara Medical Journal, 26(2), 63-67, 2013.

[25] S. Güriş, E. Akay, B. Güriş, E-views ile Temel Ekonometri, Der Yayınları, İstanbul, 2017.

[26] Ö. Ünver, H. Gamgam, B. Altunkaynak, SPSS Uygulamalı Temel İstatistik Yöntemler, Seçkin Yayıncılık, İstanbul, 2016.

[27] C. Aktaş, "Türkiye'nin turizm gelirini etkileyen değişkenler için en uygun regresyon denkleminin belirlenmesi", Doğuş Üniversitesi Dergisi, 6 (2), 163-174, 2005.

[28] W. Wang, Z. Xu, "A heuristic training for support vector regression", Neurocomputing, 61, 259-275, 2004.

[29] Y. Gültepe, "Makine Öğrenmesi Algoritmaları ile Hava Kirliliği Tahmini Üzerine Karşılaştırmalı Bir Değerlendirme", Avrupa Bilim ve Teknoloji Dergisi, 16, 8-15, 2019.

[30] S. Çınaroğlu, "Sağlık harcamasının tahmininde makine öğrenmesi regresyon yöntemlerinin karşılaştırılması", Uludağ University Journal of The Faculty of Engineering, 22(2), 179-200, 2017. 